\title{
CORPO, GÊNERO E SEXUALIDADE NO COTIDIANO ESCOLAR: POSSÍVEIS OLHARES
}

\author{
Carolina Sobreira Cesar \\ Centro Universitário de Volta Redonda (UNIFOA), Volta Redonda, Rio de \\ Janeiro, Brasil
}

\begin{abstract}
Resumo: A escola é marcada por conflitos e tensões sociais que influenciam o ensino e a aprendizagem: inovações tecnológicas, diversidade de comportamentos, novas configurações familiares, diversidade religiosa, cultural e étnica. Nessa perspectiva, percebemos uma temática que emerge como problema em meio a tantas questões: gênero, sexualidade e o modo como a escola se posiciona diante dos discursos e práticas discriminatórias. Assim, esta pesquisa investigou o currículo praticado e sua relação com o gênero e a sexualidade no cotidiano de uma escola pública do município de Barra Mansa-RJ . A metodologia se deu por intermédio dos Estudos do Cotidiano e os instrumentos foram entrevistas semiestruturadas e o caderno de campo. Percebemos que a construção de gênero e sexualidade perpassa questões sócio históricas e culturais, que buscam normalizar comportamentos e atitudes no chão da escola.
\end{abstract}

Palavras-chave: Gênero. Sexualidade. Cotidiano Escolar. Ensino Fundamental.

INTRODUÇÃO

A escola é marcada por múltiplos conflitos e tensões que influenciam o processo de ensino e aprendizagem: inovações tecnológicas, diversidade de comportamentos, novas configurações familiares, novos papéis sociais, diversidade religiosa, cultural, étnica, movimentos sociais, resultando em comportamentos alterados e violentos d@s alun@s ${ }^{1}$ (COLLING, 2009). No entanto, como profissionais de Educação Física, percebemos que uma temática emerge na atualidade como um problema em meio a todas essas questões, mobilizando nossa atenção: 0 gênero e a sexualidade, e em decorrência, o modo como a escola se posiciona diante dessas dificuldades.

Assim, o espaço escolar se depara com a diversidade que emerge da complexa rede social, e se torna um local importante para a discussão referente aos direitos humanos, inclusão e respeito às diferenças, de maneira a sensibilizar estudantes, professores e outros membros escolares em torno do debate sobre o papel que a referida instituição desempenha em prol desta questão (SCHINDHELM; HORA, 2015). Nessa linha 
de pensamento, cabe ressaltar que a sociedade está influenciada por um imaginário colonial moderno que se caracteriza por seu caráter hegemônico, monocultural e hierarquizante, pois emerge como uma referência ou modelo de comportamento: masculino, branco, católico, heterossexual, dentre outros. Esse modelo impacta a sociedade concebendo aquele que se encontra sob outro registro como sendo o "outro", 0 diferente, 0 estranho, 0 anormal (SANTOS, 2003). Um dos desafios em questão é: como a escola pode se tornar um espaço de diálogo sobre a diversidade e os direitos humanos?

Considerando que este estudo emerge de uma dissertação de mestrado, o objetivo do trabalho foi investigar o currículo praticado e sua relação com o gênero e a sexualidade no cotidiano de uma escola pública localizada no município de Barra MansaRJ. Especificamente, buscamos o seguinte percurso: investigar no Projeto Pedagógico da escola e nas práticas educativas indícios de um currículo pensadopraticado (OLIVEIRA, 2012), tendo como centralidade a discussão de gênero e sexualidade.

No estudo, optamos pela Pesquisa com o Cotidiano (FERRAÇO, 2007), pois como docente da escola estávamos imersos, mergulhados nas produções cotidianas desse espaço. Cabe ressaltar que, apesar de estar lecionando nessa escola desde 2011, 0 processo de investigação se desenvolveu ao longo do ano de 2015. 0 foco desse estudo foram @s alun@s dos anos iniciais do Ensino Fundamental, no turno vespertino, com faixa etária compreendida entre seis e dez anos. A opção pela pesquisa na referida faixa etária se deve por integrarmos o corpo docente e ministrarmos as aulas de Educação Física para os anos iniciais da instituição, bem como pela percepção de situações complexas no cotidiano escolar envolvendo a temática de gênero e sexualidade.

Dessa forma, buscamos considerar, a partir dos pressupostos da pesquisa com os cotidianos, as ações e experiências de cada sujeito, pois esses carregam consigo valores que reproduzem e transmitem, mas que também criam, nos contatos que fazem entre si em redes de conhecimento, outras produções que a razão moderna desconsidera (ALVES, 2001). As entrevistas foram realizadas no período destinado às reuniões e discussões pedagógicas (TD) e com o uso de um roteiro a partir da temática: sexualidade e gênero. 0 uso do referido instrumento emerge da perspectiva de Alves (2001), na tentativa de mergulhar no cotidiano com todos os sentidos, na intenção de ouvir, ver, intuir.

A escola possui dez professoras que atuam nos anos iniciais do Ensino Fundamental. As entrevistas foram realizadas com uma professora de cada ano de escolaridade. A inclusão das docentes na pesquisa seguiu os seguintes critérios: compor o quadro efetivo da prefeitura de Barra Mansa, antiguidade na escola e residência na comunidade. Metodologicamente, as docentes foram denominadas, a título de apresentação no texto, como: P1, P2, P3, P4 e P5, de acordo com o ano de escolaridade em que atuam.

O caderno de campo nos permitiu registrar observações, narrativas das crianças, dos docentes e da equipe pedagógica, bem como anotar episódios ocorridos durante as aulas de Educação Física. Tal perspectiva permitiu a observação junto aos sujeitos da pesquisa, sendo considerado, portanto, "como documento importante para se estudar os dilemas da prática de ensino" (EL HAMMOUTI, 2002, p.16). Em relação aos alun@s, optamos por não numerá-los, como realizado com as docentes, por suas entradas 
nos episódios do caderno de campo. Outrossim, optamos por utilizar nomes fictícios para que suas identidades fossem preservadas.

Com relação à análise documental, utilizamos livros didáticos e o Projeto Político Pedagógico como fonte de informação, na intenção de complementar os dados da pesquisa, apresentando indícios e sinais das práticas cotidianas dos docentes. A escolha por tal procedimento se deve à diversidade de dados "que deles podemos extrair e resgatar justifica o seu uso em várias áreas das Ciências Humanas e Sociais porque possibilita ampliar o entendimento de objetos cuja compreensão necessita de contextualização" (SÁ-SILVA; ALMEIDA; GUINDANI, 2009, p 2).

Por fim, a intenção desse projeto não é defender ponto de vista de um ou outro grupo, mas tentar acompanhar os processos que envolvem a questões de gênero e sexualidade que singularizam o espaçotempo investigados.

\section{EDUCAÇÃO E PÓS ESTRUTURALISMO}

Para Louro (2007a), não devemos considerar apenas as características físicas como fonte das distinções, mas as mudanças que acontecem na forma de existência e exercício do poder entre homens e mulheres, o que Foucault descreve em um dos seus discursos no Collège de France: a biopolítica. 0 autor ressalta que é a maneira pela qual a sociedade racionaliza os "problemas propostos à prática governamental, pelos fenômenos próprios a um conjunto de seres vivos constituídos em população: saúde, higiene, natalidade, raças" (FOUCAULT, 1997, p.89).

Assim, a identificação que se dá a um corpo vai depender do contexto cultural em que o indivíduo está inserido, por meio das linguagens e valores que tal contexto dispõe e adota (FOUCAULT, 1997). Para o autor, em muitos momentos, em decorrência do agenciamento da vida dos sujeitos pelo estado, por intermédio do poder, aqueles considerados anormais ou fora do padrão sofrem preconceitos e constrangimentos relacionados a seu corpo, desejos e pensamentos, passando por um processo exclusório e, em alguns momentos, até violento.

Assim, a biopolítica induz e incita um dispositivo de poder disciplinar que tem no desejo um dos seus principais pilares e, em uma sociedade patriarcal, machista, católica, acaba se tornando um mecanismo de assujeitamento. Nesta linha de pensamento, a dinâmica que se estabelece a partir do gênero e da sexualidade, e dos processos que constituem as práticas sexuais, deve ser exercida com discrição e, de forma 'natural', devendo ser adotadas por todos. Diferentemente das práticas consideradas desviantes que ocorrem por meio de jogos de poder na marginalidade.

Neste sentido, ressaltamos que este estudo busca a sua aproximação a correntes teóricas que respeitam as peculiaridades, e estão ligadas a movimentos sociais que promovem novas articulações entre sujeito e conhecimento, privilegiando as histórias e experiências dos que estão neste espaço social de exclusão.

Tal perspectiva pode nos levar a pensar as questões socioculturais por outro viés, em que as instituições, o poder e as formas de ser e estar no mundo serão concebidos e produzidos dinamicamente.

Ao assumir a perspectiva pós-estruturalista, torna-se necessário abandonar categorias fixas e quadros classificatórios, pois este estudo, ao optar pelas questões da 
sexualidade e do gênero, segue a ótica dos estudos culturais, admitindo os deslizamentos e fugindo à tentativa do controle e da fixidez. Sabemos que os homossexuais, negros e mulheres são exemplos de grupos que se uniram com o propósito de combater toda forma de imposição de regra, controle de conduta e valores previamente impostos, padronizando as múltiplas formas de perceber e viver o mundo. Portanto, a Teoria Queer se apresenta como uma corrente teórica e metodológica que busca estudar e intervir junto a esses grupos.

O referido termo surgiu nos Estados Unidos, na década de 1990, e traz consigo uma carga negativa aos olhos da sociedade atual, mas que para gays e lésbicas e/ ou simpatizantes da orientação homossexual serviu para definir um grupo disposto a lutar contra a normalização que nos é imposta historicamente. É com o intuito de romper com a forma de controle e dominação, por meio da análise crítica e da desconstrução dos discursos sobre a normalidade, que se apoiam os teóricos Queer quando passam a questionar a regra, o normal e os binarismos conceituais, que para Jacques Derrida (1972) estão presentes na lógica ocidental, pois buscam visibilizar as violências e injustiças sofridas pelo descumprimento das normas e convenções socioculturais.

Afirmar ou negar a identidade de cada um sempre irá depender de como sua diferença ou semelhança será recebida pelo outro. Então, a interdependência de sujeitos se torna indispensável, pois é a partir daí que se constrói um limite. E desse limite surgirão novas formas de contestação da norma, a desconstrução de conceitos e, então, o surgimento de novas práticas sociais e novas relações entre os sujeitos. E como se aplica essa teoria na área da Educação? Como a teoria Queer rompe com a normalização no cotidiano escolar? É possível pensar para além dos binarismos e repensando a sexualidade, os gêneros e as corporeidades em uma perspectiva dinâmica?

A intenção não é impor a ideia Queer e seus pressupostos, mas questionar o que é considerado ideal, buscando uma nova produção de sujeitos que não sejam previamente estabelecidos, mas capazes de compreender as diferenças e seu processo de produção na construção do "eu". $E$, nessa construção, perceber que, para que a individualidade exista, o sujeito precisa do outro e suas peculiaridades.

Assim, se constitui a pedagogia e o currículo Queer, dando à discussão sobre a diferença, do eu com o outro, uma posição de destaque no âmbito educacional e descontruindo 0 processo que irá tornar alguns sujeitos normalizados e outros marginalizados, evidenciando a heteronormatividade e demonstrando a necessidade da discussão das normas sociais regulatórias para garantir a identidade sexual legitimada (LOURO, 2008b). Para a autora, infelizmente, para uma aplicação efetiva, na prática, da pedagogia e do currículo Queerfaltam alguns ajustes, como a definição de um objetivo, as indicações de como agir diante dos questionamentos da equipe pedagógica e dos educandos e a forma que serão mediados os debates e as discussões so bre um tema ainda tão delicado. Por esses e outros motivos, a teoria Queeré uma incerteza perturbadora e arriscada, mas que nos faz refletir sobre nossos pensamentos e condutas na sociedade.

$\mathrm{Na}$ escola, os temas sexualidade e gênero são introduzidos aos alun@s, em sua maioria, pelo professor de Ciências, quando o conteúdo é o corpo humano, mas o que acontece, além da parte física e estrutural, não os é apresentado, porque a escola segue 
CESAR, C. S.

padrões tradicionalistas, canônicos e normalizadores, nos quais o estudante é moldado numa regra e, caso saia desse modelo, poderá fug ir ao controle da instituição. Porém, não podemos continuar fechando os olhos para as transformações socioculturais e aos inúmeros movimentos sociais, que reivindicam seus direitos.

\section{CORPO E SEXUALIDADE NO COTIDIANO DA ESCOLAR}

Neste momento iniciaremos a discussão dos dados produzidos (PAIS, 2003) a partir do documento referência da escola investigada (Projeto Político Pedagógico - PPP), do livro didático, o caderno de campo e as entrevistas realizadas com docentes e equipe diretiva. Inicialmente nos detivemos no estudo do Projeto Político Pedagógico da instituição pesquisada para buscar pistas sobre as diretrizes da unidade educacional para o desenvolvimento das ações educativas sobre a temática sexualidade. 0 documento possui diversos objetivos específicos que determinam as ações que a escola deve desenvolver, dentre eles encontramos o seguinte objetivo:

Priorizar os temas transversais que compõem os PCNs, por envolverem problemáticas sociais, atuais e urgentes, consideradas de abrangência nacional e até mesmo mundial (PROJETO POLíTICO PEDAGÓGICO, 2015).

Parece-nos que a referida ação institucional se aproxima da temática sexualidade, pois os Parâmetros Curriculares Nacionais (BRASIL, 1997) propõem temas transversais relacionados ao desenvolvimento da prática da cidadania e às questões sociais, dentre eles a orientação sexual que estabelece diálogo com a temática desta pesquisa. Portanto, percebemos que o objetivo supracitado, indiretamente abre possibilidades para as ações educativas que tenham a temática sexualidade como centralidade, pois ao citar os temas transversais de uma maneira generalizada, permite, indiciariamente (GINZBURG, 1989), que os docentes utilizem todos os temas transversais: Pluralidade Cultural, Saúde, Meio Ambiente, Ética e Orientação Sexual.

Neste sentido, Michel Foucault (2002) nos ajuda a compreender como o discurso, de maneira pronunciada ou escrita, é controlado e vigiado pela lei, que cuida da maneira como esse será concebido. 0 autor ainda ressalta que, na sociedade moderna, nem sempre temos o direito de falar qualquer coisa ou dizer tudo o que queremos, porque, dependendo do assunto, o discurso pode sofrer interdições. Assim, considerando a perspectiva foucaultiana, percebemos na leitura do referido documento - PPP -, que o tema sexualidade não está ausente, mas emerge do "não dito", pois se partirmos do pressuposto de que os PCN direcionam as ações a serem desenvolvidas na escola, é esse documento que explicita como a escola deve conceber tal tema (sexualidade). $\mathrm{Na}$ intenção de problematizar as questões supracitadas, ficamos a refletir: será que, de fato, a escola optou por citar os PCN e seus temas de maneira generalizada como um recurso de interdição da temática sexualidade? Ao ser questionada sobre o desenvolvimento de um possível projeto na escola a direção menciona que:

um projeto sobre sexualidade seria incorporado ao PPP nesta nova versão, porque gênero e sexualidade são temas muito importantes atualmente e que os alunos es- 
tão com a sexualidade muito aflorada e precisam de instruções (Entrevista concedida em 29 de Setembro de 2015).

Sabemos que os PCN, a partir do tema Orientação Sexual, propõe à escola a promoção de um trabalho de esclarecimento e a elaboração de dúvidas sobre a sexualidade, a fim de aliviar possíveis tensões e conflitos dentro do espaço escolar, bem como colaborar na promoção da saúde da criança e do adolescente, possibilitando a realização de ações preventivas às doenças sexualmente transmissíveis (DST), e de maneira mais específica à AIDS. Para os dois primeiros ciclos do Ensino Fundamental, o referido documento apresenta os seguintes blocos de conteúdos a serem desenvolvidos: Corpo: matriz da sexualidade; Relações de gênero e Prevenção às Doenças Sexualmente Transmissiveis (DSTS)/AIDS.

O primeiro bloco de conteúdos Corpo: Matriz da Sexualidade propõe uma abordagem do corpo para além de sua anatomia e funcionamento. Além de concebê-lo como "um todo integrado, de sistemas interligados que inclui emoções, sentimentos, sensações de prazer/desprazer, assim como as transformações nele ocorridas ao longo do tempo" e os fatores culturais que ajudam na construção e percepção do corpo (BRASIL, 1997, p. 96). Tal bloco inclui a sexualidade como uma parte constituinte do corpo, necessária e desejável, utilizando várias áreas do conhecimento para compreender como esta temática é expressa em outras culturas, suas regras e interdições. Apesar de, inicialmente, esse bloco de conteúdo mencionar que não se prende à questão anátomofisiológica, no transcorrer do documento percebemos a valorização do corpo ainda na perspectiva de seu funcionamento, como observado no seguinte trecho do documento:

O conhecimento do corpo e de seu funcionamento propicia uma maior conscientização da importância da saúde e da necessidade de ações não só curativas, mas também preventivas (BRASIL, 1997, p.97).

Ao longo de nossas pesquisas na literatura percebemos que diversos trabalhos ainda são desenvolvidos no cotidiano escolar, tendo como finalidade a discussão da sexualidade na perspectiva anátomo-fisiológica (BORGES, 2016). Fraga (2013) nos diz que o corpo pode possuir vários sentidos quando é investido por um poder que o regula e impõe limitações e obrigações para além da sua condição fisiológica. Portanto, o corpo analisado na escola, somente na perspectiva biológica, faz referência ao que 0 autor vai denominar de retórica anatômica, ou seja, uma abordagem somente da sua funcionalidade. Com relação aos conteúdos dos PCN (1997) referentes à Orientação Sexual - ciclos um e dois do Ensino Fundamental -, o documento apresenta em seu segundo bloco de conteúdos o seguinte tema: Relações de Gênero.

Tal documento apresenta a seguinte definição: "conjunto das representações sociais e culturais construídas a partir da diferença biológica dos sexos" (BRASIL, 1997, pp. 98-99). E ainda reitera que deve ser questionada a rigidez dos padrões de condutas exercidos para homens e mulheres, e a flexibilização dos padrões que permite a expressão de potencialidades existentes em cada ser humano, dificultada pelo estereótipo de gênero. 
Entretanto, percebemos que o documento não rompe com o modelo que concebe o gênero como sexo, portanto com um atributo anatômico, pois menciona que o gênero 'toma-se o desenvolvimento das noções de 'masculino' e 'feminino' como construção social" (p. 99). 0 que buscamos salientar é que as formas de expressão das referidas identidades como práticas corporais podem ser problematizadas a partir das noções de heterossexuais, homossexuais, bissexuais e transexuais. As narrativas das docentes reproduzem tal binarismo:

P1: Gênero é masculino e feminino pra abreviar, né, se não entender. E a sexualidade é o conhecimento do corpo assim. Aí já vai um pouco pra questão da libido, né. P2: Pra mim o gênero é homem e mulher a opção que a pessoa escolhe, seria o gênero, pra mim. E a sexualidade é aquela questão que a pessoa fica mais aflorada. P3: Gênero feminino e masculino. Sexualidade seria a opção? Não sei. Os desejos. P4: Gênero é feminino, masculino e sexualidade eu acho que seja talvez a escolha que a pessoa faz com relação a que gênero ela vai se relacionar, eu acho que é isso. P5: Pra mim o gênero é o que a gente já nasce, sou do gênero feminino e a sexualidade eu posso desenvolver outro gênero, talvez, masculino, por virar lésbica, né.

Percebemos que nas narrativas das professoras sobre o gênero se reproduz 0 conteúdo do documento base da escola (PCN) para a discussão sobre a temática de gênero e sexualidade, que, segundo os autores, não vai além do binarismo já conhecido e esperado (DUSCHATZKY; SKLIAR, 2000). Fraga (2013), ao discutir tal problema menciona que, ao tomarmos como modelo o sentido tradicionalmente atribuído às referidas identidades - masculinos e femininos -, permanecemos com uma crença de que existe um destino anatômico já estabelecido para cada uma delas. Até que ponto as ações desenvolvidas no cotidiano da escola pesquisada estão enredadas a essa forma de pensar o mundo? Alguns episódios apreendidos em caderno de campo durante as aulas de Educação Física na escola investigada revelam indícios (GINZBURG, 1989) dessa forma pensamento:

Episódio 1: Futebol é 'coisa' de homem - Ferraço (2007, p. 74), nos adverte que as pesquisas com 0 cotidiano nos remetem a uma ação enquanto professorpesquisador. 0 autor menciona que "escutar os sujeitos das escolas para, a partir dessa escuta e com eles, fortalecer processos contra-hegemônicos de políticas educacionais cotidianas", em nosso caso, é intervir no cotidiano na tentativa de enfretamento aos processos excludentes que emergem das questões de Gênero e Sexualidade.

O episódio do dia dois de junho de 2015 emergiu durante a aula de Educação Física. A aluna nos procurou e expôs a seguinte questão:

Luiza: Tia, os meninos não querem me deixar jogar porque eu sou menina e eles falaram que futebol é coisa de homem. (Episódio do dia 02 de junho de 2015).

Ao sermos procuradas pela aluna, buscamos intervir na aula, pedindo a atenção da turma e iniciando uma discussão sobre papéis pré-estabelecidos para homens e mulheres na nossa sociedade. Questionamos por que os meninos achavam que futebol deveria ser praticado somente por homens e ouvimos as seguintes respostas: 
Carlos: Ah tia, porque quem joga futebol é só homem.

Paulo: Porque é normal, ué.

Davi: Ah tia, fala sério. Mulher jogando bola, claro que não.

Problematizamos com os alunos evidenciando que o futebol é um esporte praticado por homens e mulheres e citamos o exemplo da jogadora Marta, eleita por cinco vezes a melhor jogadora de futebol do mundo. Posteriormente, solicitamos pesquisas sobre profissões julgadas preferencialmente masculinas que também são exercidas por mulheres, para posterior debate. Cabe ressaltar que, buscamos realizar tais intervenções pautadas na ótica de Oliveira (2012), pois acreditamos no currículo como criação cotidiana e se constitui enredadado às redes de subjetividades sendo, por isso, tecido de modo singular (CERTEAU, 1994). Salientamos também que futebol é o esporte preferido dentre os brasileiros, e é tradicionalmente praticado, em sua maioria, por homens, e que, mesmo jogado por brincadeira, não deixa de ter certa seriedade (FRAGA, 2013). Nesse jogo, posturas consideradas agressivas são vistas com naturalidade por seus participantes. Para 0 autor, este é um espaço onde se demonstra a virilidade masculina.

$\mathrm{Na}$ aula seguinte foram entregues figuras de mulheres atuan do como motorista de taxi e ônibus, caminhoneiro, frentista, soldador, pedreiro e trocador de ônibus. $E_{\text {, }}$ diante das pesquisas e imagens trazidas pelos alun@s, apresentamos a seguinte questão: Homens e mulheres podem exercer as mesmas profissões e ter os mesmos papéis sociais? Boaventura de Souza Santos (2003, p. 56) menciona que "temos o direito a ser iguais quando a nossa diferença nos inferioriza e temos o direito a ser diferentes quando a nossa igualdade nos descaracteriza". Portanto, propusemos um debate que tivesse como pressuposto a noção de equidade social, conforme ressalta Azevedo (2013, p. 138):

Frise-se, sociedade em que há diversidade e diferenças e que é formada por indivíduos desiguais. Assim, não se pode usar o "direito igual" para todos, ou seja, não se pode tratar igualmente os desiguais, pois, assim, a desigualdade é perpetuada.

Nessa ótica, no cotidiano escolar nos deparamos com as relações de poder que emergem de uma sociedade que impõe verdades por meio de discursos, gerando desigualdade e exclusão social daqueles considerados marginalizados. Segundo Goellner (2011.p 82), "quando meninas apresentam um perfil de habilidade e comportamento mais agressivo para o jogo, muitas vezes, sua feminilidade é colocada em suspeição", pois o registro da modernidade estabelece um papel e um comportamento social para a mulher. Simultaneamente, esse imaginário moderno e colonizador estabelece que os meninos que não se adaptam ao esporte "sobretudo às práticas coletivas, também tem colocado em dúvida a sua masculinidade" (GOELLNER, 2011.p 82).

Talvez, no pensamento dos meninos, a aluna não poderia participar do jogo porque, segundo Foucault (2002), não atendia aos preceitos das normas estabelecidas, ou seja, o processo normalizador, que classifica e hierarquiza o imaginário colonial moderno, estabelece em seu registro que, não sendo homem, ou não sabe ou não se pode jogar o 
futebol. Após a referida discussão, a turma e especificamente os meninos, entenderam que o futebol pode ser praticado por homens e mulheres.

Ainda no tema futebol e com os alun@s do terceiro ano, apresentamos o próximo episódio do caderno de campo também ocorrido nas aulas de educação Física.

Episódio 2: Menina gosta de boneca e menino de futebol - Ao nos aproximarmos de alguns alun@s da turma do terceiro ano, notamos que o aluno João estava com uma expressão fechada e parecia chateado. Então, perguntamos se alguma coisa havia acontecido. 0 excerto da pesquisa revela o problema:

J oão: Tia, o Ricardo disse que eu sou menina e que eu só sei fazer coisa de menina, só porque eu não quis brincar de futebol com os meninos (Episódio do dia $27 \mathrm{de}$ abril de 2015).

Como podemos perceber, os alun@s reproduzem o imaginário estabelecido por uma sociedade colonial moderna, que busca determinar padrões de comportamentos para os papéis sociais de homens e mulheres, conforme discutido ao longo do trabalho.

$\mathrm{Na}$ intenção de realizar uma intervenção imediata, chamamos o aluno Ricardo e problematizamos algumas questões: será que todo menino gosta de futebol? Até que ponto as meninas só gostam de brincar de boneca? Posteriormente, ressaltamos ao aluno que as mulheres também são expectadoras e admiradoras de jogo de futebol, o que não as tornam masculinizadas. Então, o aluno se espantou e, ainda preso ao paradigma explicitado, fez a seguinte assertiva:

Ricardo: Mas, tia, você é menina e menina brinca de corda e boneca e menino de futebol (Episódio do dia 27 de Abril de 2015).

Devido à relevância do tema em questão, pedimos à turma para que aqueles que gostassem de jogar futebol levantassem a mão. Para surpresa de alguns meninos, somente três alunas, no total de dez dessa turma, não levantaram a mão. Então, perguntamos quem gostava de pular corda e toda a turma levantou a mão, incluindo 0 Ricardo, o aluno que havia feito o comentário mencionado. Posteriormente, argumentamos que podemos gostar e brincar de várias atividades, independente do nosso gênero e da atividade: futebol, pular corda ou brincar de boneca.

Neste momento a discussão de Santos (2006) se faz relevante, pois se reporta aos processos de regulação e controle estabelecidos pela racionalidade colonial moderna: "A desigualdade e a exclusão são dois sistemas de pertença hierarquizada. No sistema de desigualdade, a pertença dá-se pela integração subordinada, enquanto que no sistema de exclusão a pertença dá-se pela exclusão" (SANTOS, 2006, p. 280). O autor, ao discutir a necessidade de democratização social, explicita dois sistemas que permitem a subordinação e exclusão do 'outro' na sociedade contemporânea. No caso supracitado, percebemos que o pensamento do alun@ está incluído no sistema que exclui meninas e meninos de determinadas práticas socioculturais, pois a sociedade, tendo como referência a razão moderna e seus atributos hierarquizantes, determina papéis sociais para cada um dos sexos. 
Percebemos, ainda, que os excertos da pesquisa apresentam sinais, pistas (GINZBURG, 1989) que refletem o discurso de rejeição (FOUCAULT, 2002), pois o olhar do discente determina que as meninas não poderiam escolher o jogo com os pés, pois estariam fora do registro de feminilidade, logo não poderiam ser consideradas femininas. Fraga (2013) argumenta que as identidades culturais são impostas aos sujeitos como uma herança já estabelecida para cada gênero, por isso a ideia dos alun@s de que somente os meninos jogam futebol e as meninas pulam corda e brincam de boneca. Outro episódio do caderno de campo que também aborda as questões de condutas sociais para homens e mulheres, a partir das características biológicas, foi durante a narrativa de um aluno sobre o filme da Cinderela.

Episódio 3: 0 Filme da Cinderela - 0 presente episódio ocorre no horário de entrada escola. Enquanto aguardávamos a turma que teria a primeira aula de Educação Física, José, terceiro ano do Ensino Fundamental, nos abordou com lágrimas nos olhos dizendo:

J osé: Tia, só porque ontem eu fui ao cinema com meu pai e disse que não queria ver filme de morte, fomos ver o filme da Cinderela. Aí agora tá todo mundo falando que eu fui ver desenho de menina (Episódio do dia 30 de março de 2015).

Prontamente respondemos ao aluno que Cinderela é um desenho para crianças e não só de menina. Ele concordou balançando a cabeça de maneira positiva sorrindo e voltou para a fila. Notamos que o padrão heterossexual influencia a maneira de agir dos sujeitos fazendo com que, culturalmente, os que não estão dentro dessa regra se tornem alvo de olhares e insinuações do outro (LOURO, 2008a), se tornando uma espécie de ameaça à ordem social, se aproximando do que Miskolci (2015) denomina de abjeção.

O sujeito abjeto se torna uma temeridade dentro da sociedade, pois sua identidade ameaça a visão homogênea da comunidade, colocando em risco o bom funcionamento da ordem. Logo, esse sujeito é rejeitado e recusado (MISKOLCI, 2015, p. 24).

Por fim, o terceiro e último bloco de conteúdos dos PCN para a temática da Orientação Sexual faz referência à Prevenção às Doenças Sexualmente Transmissíveis/Aids, e tem como objetivo "a promoção de condutas preventivas, enfatizando-se a distinção entre as formas de contato que propiciam risco de contágio daquelas que, na vida cotidiana, não envolvem risco algum" (BRASIL. 1997, p 100). É relevante ressaltar que, trazer os PCN para o debate se revelou necessário por ser este documento utilizado como referência no Projeto Pedagógico da escola.

Como podemos perceber, o bloco de conteúdos - Prevenção às Doenças Sexualmente Transmissiveis/Aids - atua na perspectiva do sexo, privilegiando apenas os modos de prevenção de doenças. Não estamos aqui dizendo que tal assunto não é relevante na escola, mas apenas ressaltando que a sexualidade, do ponto de vista da maneira como os sujeitos fazem uso dela, problematizando, requer a discussão do modo como ela é utilizada: hetero, homo, bi, trans. 0 referido bloco também sugere a discussão sobre o corpo e os serviços oferecidos pelos sistemas de saúde. Ao apontar a sexualidade como um tema transversal capaz de problematizar os conflitos na escola, os PCN direcionam o seu discurso para a maneira como docentes irão lidar com a complexidade 
CESAR, C. S.

do assunto. Porém, ao incorporar em suas propostas e aos blocos de conteúdos a questão da promoção da saúde e ações para a prevenção das DST/AIDS, abre uma lacuna para que a sexualidade seja encarada e discutida somente no âmbito do sexo, como observamos no trecho abaixo que sugere:

Enfatizar as formas de prevenção como o uso de preservativo - proteção necessária para inibir o contágio por contato sexual(BRASIL, 1997, p.101).

0 que se percebe, diante das informações desse bloco de conteúdo, é um discurso voltado para a higienização da sexualidade, fazendo com que o indivíduo seja responsável por sua higiene física e moral, além dos comportamentos referentes ao sexo, numa perspectiva somente biológica e reprodutiva, deixando de fora as questões de gênero e sexualidade infantil, como se essa temática fosse somente apropriada para uma idade específica, a adolescência (BRAGA, 2006). Neste sentido, a autora argumenta que a orientação sexual nas escolas se apresenta como mais um dispositivo da pedagogia de prevenção existente nas escolas e que a temática da sexualidade está muito mais articulada aos dispositivos de controle que à perspectiva de problematização e debate.

Para Miskolci (2015, p.42), a sexualidade envolve afeto, indo além do sexo em si, pois expressa nossas vontades mais secretas, e por isso se tornou um dispositivo de controle. Portanto, a ausência de um objetivo explícito no PPP, abarcando a temática estudada, bem como a articulação do referido documento ao PCN, nos leva a refletir so bre os múltiplos discursos dos alun@s, e nos possibilita perceber que a concepção de sexualidade que emerge no cotidiano escolar prioriza a ótica hierárquica e classificatória da racionalidade moderna. A narrativa da orientadora pedagógica explicita tal cenário:

Assim, se um pai questionar, porque alguns pais não concordam que esse tema seja debatido dentro da escola. Então a gente procura ser o mais claro possível na parte até científica mesmo, o que é, o que pode acontecer com o corpo do menino e com a menina (Entrevista concedida em 25 de setembro de 2015).

A Orientadora Educacional, ao se posicionar diante da temática de sexualidade, menciona que a temática é abordada apenas para os alun@s do quinto ano. A docente afirma que a explanação é bem simples para evitar problemas e que a fala é mais voltada para a parte científica. Ao tentar evitar possíveis questionamentos dos pais sobre a maneira como a temática sexualidade é desenvolvida no ambiente escolar, percebemos que a orientadora se mantém articulada à noção de interdição de Foucault (2002), na tentativa de administrar as 'coisas' a serem 'ditas'. Neste momento, me recordo de Fraga (2013, p 132.) e da administração do discurso. Para o autor, nas sociedades modernas falava-se sobre o sexo de uma maneira prolixa na tentativa de regulação: "Para uma administração eficiente era importante estruturar um saber so bre o sexo que organizasse um vocabulário autorizado, mas de circulação restrita" (grifo nosso).

Até que ponto a parte científica mencionada no depoimento da professora, emerge como uma fala autorizada? Se em um período histórico a igreja autorizava e restringia o discurso sobre o sexo, será que parte deste papel agora cabe à escola? 0 que buscamos enfatizar é a tentativa da escola de evitar o debate com temas polêmicos utilizando os conhecimentos científicos, portanto restrito às questões de saúde e preven- 
ção, uma maneira de neutralizar o discurso so bre a sexualidade, o que jamais deixará de ser uma atitude política. A escola prefere insistir no discurso que segue a norma, se limitando ao que os responsáveis querem que seja 'dito'.

$\mathrm{Na}$ continuação da narrativa da orientadora, notamos que, ao manter um discurso somente na esfera biológica, a mesma exclui qualquer outra identidade de gênero que não seja masculino e feminino, inviabilizando a discussão sobre a construção sócio histórico e cultural que envolve gênero (LOURO, 2007b). Dessa maneira nos perguntamos: qual seria o discurso da escola sobre aqueles alun@s que se encontram fora deste modelo anátomo-fisiológico da definição de gênero presente nos PCN e no PPP da Escola? Não seria o momento de deixar para trás a fala mais simples e iniciar uma abordagem contextualizada dentro de uma perspectiva que envolva a questão das diferenças? Por fim, o último documento analisado foi o livro didático, por se caracterizar como mais um dispositivo de controle que determina o que é normal. Diante disso, buscamos questionar: como a questão do corpo se apresenta no livro? Qual a concepção de gênero e sexualidade que emerge em tal documento?

0 primeiro ano do Ensino Fundamental não apresenta livro didático de Ciências, porém a professora (P1) dessa fase, em sua entrevista, disse que, mesmo sem material fornecido pela rede municipal, trabalha o corpo humano:

P1: Sim, isso faz parte do currículo trabalhar o corpo, né? Cuidar, higiene pessoal, conhecimento do corpo, a funcionalidade de cada parte do corpo. A gente trabalha sim (Entrevista cedida em 22 de setembro de 2015).

Como recurso alternativo, ela utiliza material próprio, jogos em grupo e sua experiência em outras instituições. Ao ser questionada so bre a abordagem de tal temática em suas aulas, a professo ra ressalta que não se recorda, e que desenvolve mais a parte de higiene corporal, como por exemplo, o cuidado com as partes íntimas. Notamos que, ao abordar somente as questões do cuidado com a higiene pessoal e as funções do corpo, a docente se preocupa somente com a questão física e biológica, deixando a sexualidade fora dessa discussão. É por essa fala que podemos identificar uma produção controlada de discurso, uma fuga ou uma manutenção da censura (FOUCAULT, 2002), pois considerando que a sexualidade ainda é um tabu, principalmente dentro da escola, talvez seja mais confortável para professora não aprofundar a referida discussão. Portanto, nos parece que a manutenção do silêncio permite que 0 monstro não se revele, não necessitando problematizar questões relevantes para o processo de emancipação social. Para o autor, a monstruosidade se caracteriza pela irregularidade do que é natural e, quando aparece, questiona o direito e 0 obriga a rever suas práticas e referências (FOUCAULT, 2001). Neste sentido, no momento em que a docente opta pelo silenciamento, o debate não acontece, ou seja, permanece o não dito e acarreta uma interdição do discurso: o poder emerge nas relações! 


\section{CONSIDERAÇÕES FINAIS}

Considerando os dados produzidos, percebemos que a construção de gênero e sexualidade perpassa questões históricas, sociais e culturais que influenciam demasiadamente na construção da subjetividade dos alun@s e, em decorrência, diferentes formas de posicionamento frente à realidade vivida. 0 pensamento hegemônico e suas normas referentes à sexualidade, ao gênero e suas concepções no processo de ensino-aprendizagem permite compreender como se desenvolveu a construção do uso do corpo desde o século XVIII até os dias atuais, prevalecendo como norma a representação masculina. A escola é um espaço que possui inúmeras aberturas e, se por um lado percebemos a presença da ordem dominante intervindo por meio de normas e padrões a serem seguidos, inviabilizando o debate sobre as diferenças que invadem o seu cotidiano - discurso de educadores e alun@s, na ausência da temática no PPP e nos livros didáticos -, por outro lado é relevante ressaltar a construção de diálogos e debates que permitam a construção de outros conhecimentos, pautados no respeito e na democratização dos espaços e do comportamento dos sujeitos.

Diante do exposto, ressaltamos que o currículo pensadopraticado (OLIVEIRA, 2012) no cotidiano da escola investigada, apesar de ter como centralidade uma monocultura que hierarquiza, classifica e discrimina pessoas e comportamentos, também busca, ao seu modo, intervir e se posicionar diante desse cenário, pois foi possível perceber discussões sobre a construção social das noções de gênero e sexualidade, já que algumas práticas educativas são debatidas e problematizadas.

Artigo recebido em: 28/08/2017 Aprovado para publicação em: 20/03/2018

\section{BODY, GENDER AND SEXUALITY IN THE SCHOOL EVERYDAY: POSSIBLE PERSPECTIVES}

ABSTRACT: School is marked by conflicts and tensions that influence the teaching and learning process, such as: technological innovations, behavioral diversity, new family configurations, religious, cultural and ethnic diversity. From this perspective, we can notice an issue that emerges as a problem among such questions: gender and sexuality, and consequently, the way schools position themselves towards speeches and discriminatory practices. This study aimed to investigate the pedagogical activities related to gender and sexuality in a public school in the city of Barra Mansa - RJ. The methodological scope of the investigation was composed through the Studies of Everyday Life, using semi-structured interviews and a field notebook. Taking in to consideration the studies developed, we can notice that the construction of gender and sexuality runs through social historical and cultural questions that seek to normalize behaviors and attitudes on the school.

KEYWORDS: Gender. Sexuality. School daily life. Primary school 


\section{CUERPO, GÉNERO Y SEXUALIDAD EN EL COTIDIANO ESCOLAR: POSIBLES MIRADAS}

RESUMEN: La escuela és marcada por conflictos y tensiones sociales que influencian la enseñanza y el aprendizaje: innovaciones tecnológicas, diversidad de comportamientos, nuevas configuraciones familiares, diversidad religiosa, cultural y étnica. En esta perspectiva, percibimos una temática que emerge como um problema en medio de tantas cuestiones: género, sexualidad y el modo como la escuela se posiciona ante los discursos y prácticas discriminatorias. Así, esta investigación investigó el currículo practicado y su relación con el género y la sexualidad en el cotidiano de una escuela publica del municipio de Barra Mansa-RJ. La metodologia se dio por medio de los Estudios del Cotidiano y los instrumentos fueron entrevistas semiestructuradas y el cuaderno de campo. Se percibe que la construcción de género y sexualidad atraviesa por cuestiones socio-históricas y culturales que busca normalizar comportamientos y actitudes en el suelo de la escuela.

PALABRAS CLAVE: Género. Sexualidad. Cotidiano Escolar. Enseñanza fundamental.

\section{NOTA}

1) A utilização metodológica do símbolo @ na grafia do texto se deve pela tentativa de posicionamento de ruptura frente ao binarismo imposto pela racionalidade moderna.

\section{REFERÊNCIAS}

BRAGA, A. V. Identidade sexual e cultura escolar: uma crítica à versão de /sexualidade contida nos PCN. Revista Iberoamericana de Educación, v. 40, n. 2, p. 1, 2006.

BRASIL. Secretaria de Educação Média e Tecnologia. Parâmetros Curriculares Nacionais: ciências naturais. Brasília. MEC/SEMTEC. 1997.

BORGES, A. L. V. et al. Erica: início da vida sexual e contracepção em adolescentes brasileiros. Revista de Saúde Pública, v. 50, n. supl. 1, p. 15, 2016.

COLLING, A. M. Relações de Poder e Gênero no Currículo Escolar. In: Corpo, gênero e sexualidade: composições e desafios para a formação docente. Rio Grande: Editora FURG, 2009.

DERRIDA, J. Margens da filosofia. Porto: Rés-Editora, 1972.

DUSCHATZKY, S.; SKLIAR, C. Os Nomes dos Outros. Reflexões sobre os Usos Escolares da Diversidade. Educação \& Realidade, v. 25, n. 2, 2000. 
CESAR, C. S.

EL HAMMOUTI, N. Diários etnográficos profanos na formação e pesquisa educacional. Revista europeadi etnografia dell'educazione, v. 1, n. 2, p. 9-20, 2002.

FERRAÇO. C. E. Pesquisa com o cotidiano. Revista Educação \& Sociedade, Campinas, v. 28, n. 98, p. 73-95, 2007.

FOUCAULT, M. Resumo dos cursos do Collège de France (1970-1982). Rio de Janeiro:J orge Zahar, 1997.

$\overline{2} 00 \overline{1}$. . Os anormais. curso no College de France (1974-1975). São Paulo: Martins Fontes. . A verdade e as formas jurídicas. Rio de J aneiro: Nau, 2002. Fontes. 2010.

Em defesa da sociedade: Curso no Collège de France (1975 - 1976). SP: Ed. Martins . Vigiar e Punir. Petrópolis. 41ª ed. Editora Vozes, 2015.

FRAGA, A. B. Corpo, identidade e bom mocismo: cotidiano de uma adolescência bem comportada. Belo Horizonte: Autêntica, 2013.

GALLO, S. Modernidade/pós-modernidade: tensões e repercussões na produção de conhecimento em educação. Educação e Pesquisa, v. 32, n. 3, p. 551-565, 2006.

GINZBURG, C. Sinais. raízes de um paradigma indiciário. Mitos, emblemas, sinais, p. 143179, 1989.

GOELLNER, S. V.; GUIMARAES, A. R.; MACEDO C. G. Corpos, gêneros, sexualidades e relações étnico-raciais: reflexões a partir de uma experiência em sala de aula. In: SILVA, F. F. da; MELLO, E. M. B. (orgs.). Corpos, gêneros, sexualidades e relações étnico-raciais na educação. Uruguaiana, RS: UNIPAMPA, 2011, p. 12-27.

GREGORI, M. F. Prazeres perigosos. Erotismo, gênero e limites da sexualidade. 2010. Tese de Doutorado. Tese de Livre Docência. Campinas, IFCH-UNICAMP.

GUIMARÃES, C. D. O homossexual visto por entendidos. Editora Garamond, 2004.

HEILBORN, M. L. Corpos na cidade: sedução e sexualidade. In: VELHO, G. Antropologia urbana. Rio de J aneiro: Editora Zahar, 2002.

LIPOVETSKY, G. Os tempos hipermodernos. Portugal: Edições 70, p. 2011.

LOURO, G. L. (org.). O corpo educado: pedagogias da sexualidade. 3. ed. Belo Horizonte: Autêntica, 2007. 
Gênero, sexualidade e educação: das afinidades políticas às tensões teóricometodológicas. Educação em Revista, v. 46, p. 201-218, 2007.

. Sexualidade, gênero e educação: Uma perspectiva pós-estruturalista. 12. Ed. Petrópolis: Vozes, 2008a.

. Um corpo estranho: ensaios sobre a sexualidade e a teoria queer. Belo Horizonte: Autêntica, 2008b.

MISKOLCI, R. Teoria Queer. um aprendizado pelas diferenças. 2 ed. Belo Horizonte: Autêtica Editora: UFOP - Universidade Federal de Ouro Preto, 2015.

MISSE, M. O estigma do passivo sexual: um símbolo do estigma no discurso cotidiano. 3 ed. Rio de J aneiro: Booklink: NECVU/IFICS/UFRJ : LeMetro/IFICS/UFRJ , 2007.

OLIVEIRA, I. B. Reflexões acerca da organização curricular e das práticas pedagógicas na EJA. Revista Educar, Curitiba, n. 29, p. 83-100, 2007.

Contribuições de Boaventura de Sousa Santos para a reflexão curricular: Princípios Emancipatórios e Currículos Pensadospraticados. Revista e-Curriculum, São Paulo, v.9, n. 2, 2012.

PAIS, J. M. Vida cotidiana: enigmas e revelações. Cortez, 2003.

PARAISO, M. A. Currículo-mapa: linhas e traçados das pesquisas pós-críticas sobre currículo no Brasil. 26a REUNIÃO ANUAL DA ANPED. Caxambú - MG, 2003.

. Pesquisas pós-críticas em educação no Brasil: esboço de um mapa. Cadernos de pesquisa, v. 34, n. 122, p. 283-303, 2004.

PETERS, M. Pós-estruturalismo e filosofia da diferença. Uma introdução. Belo Horizonte: Autêntica, 2000.

PORTINARI, D. A Gentrificação do Queer e as intensificações do biopoder. 37ª Reunião Nacional da ANPEd. Florianópolis: UFSC, 2015.

SÁ-SILVA, J. R.; ALMEIDA, C. D. de; GUINDANI, J. F. Pesquisa Documental: pistas teóricas e metodológicas. Revista Brasileira de História e Ciências Sociais, Número I, 2009.

SANTOS, B. de S. Reconhecer para libertar. os caminhos do cosmopolitanismo multicultural. Rio de J aneiro. Civilização Brasileira, 2003. 
CESAR, C. S.

SCHINDHELM, V. G.; HORA, D. M. Sexualidade, Gênero e Aprendizagens Narrativas no Currículo Escolar da Infância. Revista Científica e-Curriculum, São Paulo, v. 13, n. 01, p. 147 - 168 jan./mar. 2015.

SILVA, T. T. da. Alienígenas na sala de aula: uma introdução aos estudos culturais em educação, v. 5, p. 190-207, 1995.

VEIGA-NETO, A. Educação e Pós-Modernidade: impasses e perspectivas. Educação online. PUC-RJ, 2006.

.; LOPES, M. C. Inclusão e governamentalidade. Revista Educação \& Sociedade, Campinas, vol. 28, n. 100 - Especial, p.947-963, 2007.

\footnotetext{
Carolina Sobreira Cesar: Possui graduação em licenciatura plena em Educação Física pela Universidade Federal Rural do Rio de Janeiro (2008). Pós-graduada nos cursos de Educação física Escolar e Psicomotricidade aplicada à educação pelas FIJ - Faculdades integradas de Jacarepaguá. Mestre em Ensino em Ciências da Saúde e do Meio AmbienteUNIFOA Professora concursada da Prefeitura Municipal de Barra Mansa e da SEEDUCRJ ministrando aulas de Educação Física para o Ensino Fundamental e Médio. E, no Colégio Anglo Americano- Unidade Volta Redonda, trabalha com a Educação Física em aulas bilíngues.

E-mail:carol.sobreira@globo.com
}

Este periódico utiliza a licença Creative Commons Attribution 3.0, para periódicos de acesso aberto (Open Archives Iniciative - OAI). 